\title{
Are members of the Anopheles fluviatilis complex conspecific?
}

\author{
Om P Singh*1, Ankita Sindhania ${ }^{1}$, Gunjan Sharma ${ }^{1}$, Shobhna Mishra ${ }^{1}$, Surya K Sharma ${ }^{2}$, Piyoosh K Singh ${ }^{3}$, \\ Manoj K. Das ${ }^{3}$ \\ ${ }^{1}$ National Institute of Malaria Research, Sector 8, Dwarka, Delhi-110077, India \\ ${ }^{2}$ National Institute of Malaria Research, Field Unit, Sector-5, Rourkela 769002 , Odisha, India. \\ ${ }^{3}$ National Institute of Malaria Research, Field Unit, Itki, Ranchi, India. \\ *Corresponding author (email: singh@nimr.org.in; dr.opsingh@gmail.com)
}

\begin{abstract}
:
Anopheles fluviatilis sensu lato, a primary malaria vector in India, was identified to be comprised of four cryptic species, provisionally designated as species S, T, U and V. However, Kumar et al. (Mol Ecol Resour, 2013;13:354-61) considered all of the then known three members of this species complex (S, T and U) conspecific. The specific status of species $\mathrm{S}$ and $\mathrm{T}$ was refuted based on the lack of sufficient barcode gap in mitochondrial-CO1 and the perceived presence of heterozygotes in populations as detected through one of the two species-specific PCR assays employed for the cryptic species identification. The existence of species $U$ was refuted claiming that earlier investigations have already refuted their existence. This conclusion is concerning because of the differential public health implications of members of the Fluviatilis Complex. Here we discuss problems associated with the $C O 1$-based barcode approach for delimitation of cryptic species, the perceived heterozygosity between species $\mathrm{S}$ and $\mathrm{T}$ based on a species-specific PCR assay, and interpretation of published reports. We demonstrated that fixed differences do exist in the ITS2-rDNA sequence of species $S$ and $\mathrm{T}$ with no evidence of heterozygotes in sympatric populations and, that the observed heterozygosity by Kumar et al. in the ITS2-based species diagnostic PCR is due to the high mispriming tendency of the Tspecific primer with species S. We infer that mitochondrial DNA-based 'barcoding gap', an arbitrary threshold recommended for species delimitation, alone, is inadequate to delimit the members of An. fluviatilis complex.
\end{abstract}

Keywords: Anopheles fluviatilis, cryptic species, barcode of life, malaria

Anopheles fluviatilis s.l. is one of the major malaria vectors in India which was recognized as a complex of four cryptic species, species S, T, U and species V (Subbarao et al., 1994; Nanda et al., 2013). The recognition of cryptic species in this species complex bears epidemiological significance owing to the contrast difference in host-feeding preference — an important determinant of malaria vectorial competence. Species $\mathrm{S}$ is highly anthropophagic (>91 percent) while species T, U and V are zoophagic (>87\%) (Nanda et al., 1996; 2012). Species $S$ was found to be an efficient malaria vector in forested areas in several states (Nanda et al., 2000, 2012; Sharma et al., 2006; Tripathy et al., 2010, Sahu et al., 2011), while species T and U were not found with sporozoite positivity (Sharma et al., 1995, Shukla et al., 1998), except for a few positive specimens of species T in Madhya Pradesh (Singh et al., 2015). Detailed bionomics of species V has not been studied yet. Species-specific differences were found in the nuclear second internal transcribed spacer (ITS2) as well as in the 28S ribosomal DNA (rDNA) (Manonmani et al., 2001; Singh et al., 2004, 2020; Chen et al., 2006), which were exploited for the development of PCR-based assays for their identification (Manonmani et al., 2001; Singh et al., 2004, 2020). However, the existence of species S, T, and U in the Fluviatilis Complex has been refuted by Kumar et al. (2013). Species S and T were considered conspecific based on the lack of the sufficient 'barcoding gap', an arbitrary threshold to delimit species, in the partial cytochrome c oxidase subunit 1 locus ( $\mathrm{CO} 1)$ and observed presence of heterozygotes as detected through one of the two rDNA- 
based species-specific PCR employed for the species identification. The specific status of the third species, species U, was refuted based on misrepresentation of the published reports. Such a report has created confusion about the specific status of cryptic species and hampered further research on the differential bionomics of members of the species complex.

DNA barcoding has emerged as a global standard for species identification which, in the case of animals, utilizes the sequence divergences at $\sim 600$ bp mitochondrial gene cytochrome oxidase 1 (CO1) for the discrimination of the closely allied species. The advent of the barcoding system has discouraged to some extent conventional methods to delimit species based on the evidences pointing to genetic isolation in cryptic species. While barcode has been successfully used for the delimitation of species in a wide array of animal taxa, it failed to delimit the species in many cases where a sufficient gap does not exist due to the incomplete lineage sorting and introgression of mitochondrial DNA. Although the use of multiple markers (nuclear and mitochondrial) has been advocated to overcome this problem owing to frequent reports of mito-nuclear discordance, but such an approach is less frequently used. In the case of An. fluviatilis, Kumar et al. barcoded species $\mathrm{S}$ and $\mathrm{T}$ and considered them conspecific merely on the basis of lack of sufficient barcoding gap between species $\mathrm{S}$ and $\mathrm{T}$ without considering fix differences in nuclear rDNA (Manonmani et al., 2001; Chen et al., 2006; Singh et al., 2006) and differences in host-feeding preference (Nanda et al., 1996, 2012).

Kumar et al. considered differences in rDNA sequences "just ribosomal DNA genetic variants" which "may not have any taxonomic significance". We argue that fixed and conserved differences in rDNA, especially in a sympatric population, are clear evidence of genetic isolation. However, due to limited data prevailing in public domain on ITS2, we generated ITS2-rDNA sequences of An. fluviatilis specimens collected from a forested belt under Odisha and West Singhbhum hills (see Supplementary file S1) where species $\mathrm{S}$ and T have been reported to be sympatric. The analysis of ITS2 sequences (species $\mathrm{S}=106, \mathrm{~T}=46$ ) confirmed two distinct and conserved types of sequences in morphologically identified An. fluviatilis, one identical to Species S (Singh et al., 2006) and the other identical to species T (Chen et al., 2006). The sequence alignment has been shown in Figure 1. The species $\mathrm{S}$ and $\mathrm{T}$ differ at a total of 14 nucleotide base positions (including 2 indels) with a genetic distance of 3.28\% (Kimura 2-parameter). No intraspecific variation in DNA sequences was observed. In species T, there were mixed bases at nucleotide positions 91 and 198 (Figure 1) which were consistently present in all species T samples. We didn't find any heterozygotes in these populations. In other words, these two sequences are fixed in a sympatric population. If we assume that the two molecular forms in respect to ITS2 are freely interbreeding without genetic constraints, we expect heterozygotes or evidence of homogenization of ITS2 sequence, that was absent. Two distinct and fixed ITS2 sequences in a sympatric population with a lack of homogenization or hybridization provide clear evidence of reproductive isolation between them.

Another argument by Kumar et al. in the favour of conspecificity of species $\mathrm{S}$ and $\mathrm{T}$ is the perceived presence of heterozygotes of species $\mathrm{S}$ and $\mathrm{T}$ in the population. Kumar et al. observed the presence of faint species T-diagnostic bands along with prominent S-specific bands in an ITS2-based species diagnostic PCR assay (ITS2-ASPCR) (Manonmani et al., 2001) in samples that were identified as Species S by another diagnostic PCR based on 28S-rDNA (Singh et al., 2004) and considered them to be heterozygotes. However, Kumar et al. didn't verify the presence of heterozygosity through DNA sequencing. We also observed the presence of faint T-diagnostic band ( $\sim 50 \mathrm{bp}$ ) in samples belonging to species $\mathrm{S}$, in addition to the prominent S-diagnostic band ( $\sim 345 \mathrm{bp}$ ) (Figure 2). Faint T-specific band can be better seen when relatively a higher amount $(10-15 \mu \mathrm{L})$ of PCR product is loaded in the well of agarose gel. However, when we sequenced ITS2 region of such samples, an unambiguous sequence corresponding to species $\mathrm{S}$, without any trace of the Tspecific sequence, was obtained (Figure 3). Had it been heterozygote, we expect mixed bases at all the nucleotide substitution positions and collapse of DNA sequence chromatogram beyond the point of indels, which were absent in all such samples. Thus, the presence of T-specific diagnostic band in species $\mathrm{S}$ can be 
either due to mispriming of T-specific primer (T-R) with species $\mathrm{S}$ or due to extremely low copy number of Tspecific ITS2 due to the intragenomic sequence variations not detectable through DNA sequence chromatogram (Sharma et al., 2016). We, therefore, checked the priming efficiency of primer T-R on five clonal ITS2 products of species S (plasmid DNA with ITS2 insert) of known sequences which were confirmed to have species S-specific ITS2 sequence and were free from PCR error. PCR was performed with primers 5.8S-F (universal primer from 5.8S rDNA) and T-R used by Manonmani et al. (2001), in stringent PCR conditions (see Supplementary file S1). We observed a prominent band (Figure 4) corresponding to the diagnostic band size of species $\mathrm{T}$ in all clonal samples confirming the high mispriming tendency of the primer. To confirm that this band is not due to the contamination of reagents or carryover of DNA or aerosol DNA, we sequenced two PCR products amplified from clonal samples. We obtained a clean sequence that was identical to species $\mathrm{S}$ (except in the T-R primer region which is derived from the primer) (Figure 5). This exhibits that $\mathrm{T}$-specific primer has the tendency of mispriming with species $\mathrm{S}$ template. In another experiment, we also checked mispriming of T-R on An. minimus s.s. samples, which have an identical sequence to species $\mathrm{S}$ in the primer (T-R) region. All the An. minimus samples ( $\mathrm{n}=10)$ tested with ITS2-ASPCR, provided false Tdiagnostic band ignoring mismatches in primer (Figure 2). We also designed and carried out an RFLP assay to check the presence of heterozygote in species S. Assuming that restriction enzymes have tremendous specificity to their recognition site, we designed species T-specific RFLP using enzyme BtsI-v2. The An. fluviatilis $\mathrm{S}$ samples including those with the observed heterozygosity in ITS2-ASPCR were subjected to this PCR-RFLP assay. All the samples $(n=27)$ with observed heterozygosity in PCR assay didn't cleaved with $B t s I-v 2$ (Figure 6). These experiments show that the observed heterozygosity in ITS2-species diagnostic assay may be due to mispriming of species T-specific primer with species $\mathrm{S}$ template. We, therefore, ruled out the possibility of the presence of heterozygotes based on ITS2-ASPCR until this is not proved through DNA sequencing.

Another plausible and strong evidence supporting the distinct specific status of species $\mathrm{S}$ and $\mathrm{T}$ is the contrast differences in their host preferences. Species $\mathrm{S}$ has been found mainly anthropophilic $(>91 \%)$ whereas species T was zoophagic (>87\%) in sympatric populations (Nanda et al., 1996; 2012).

Kumar $e t$ al. also refuted the existence of species $U$ without any supporting data generated by themselves. Albeit, the argument for such refutation is based on an erroneous interpretation of previous findings. Kumar et al. stated "earlier investigations have refuted the existence of species $U$ " without citing any reference of the published report. However, in the latter part of their paper, they referred to Chen et al. (2006) in support of their statements. Citing Chen's reference, the authors stated "... however, genetic introgression between species $U$ and species Thad been described in some parts of India (Chen et al. 2006)”. This is not in agreement with the statement by Chen et al. (2006) concerning the Indian population. Conversely, Chen et al. (2006) have clearly stated "We sequenced the D3 region (of 28S rDNA) from 12 individuals of species $T$ and eight of species $U$ from Uttar Pradesh in north-western India and the sequences were consistently distinct, albeit for a single substitution". Chen et al. (2006) further concluded "Therefore, An. fluviatilis $T$ and $U$ may be regarded as well-defined but very closely related species". Chen et al. (2006) also recorded differences of six bp in ITS2 between species T and U. The absence of heterozygotes through chromosomal (Subbarao, 1994) and molecular markers (Chen et al., 2006) in a population where species T and $\mathrm{U}$ are sympatric (Uttarakhand, undivided Uttar Pradesh) evident the presence of reproduction barrier between these two species. Moreover, differences in palpal ornamentation of sympatric species $\mathrm{T}$ and $\mathrm{U}$ have also been noted (Sharma et al, 2020) Introgression in these species, if any, is a subject of further research.

Kumar et al. also endorsed an already resolved controversy on the conspecificity of species $\mathrm{S}$ with $A n$. harissoni prevailed in literature in the past (Garros et al., 2005; Chen et al., 2006) ignoring subsequent work by Singh et al. (2006). We would like to mention that the inference that species $\mathrm{S}$ is conspecific with An. harissoni was based on the circumstantial evidence of similarity in a $336 \mathrm{bp}$ conserved stretch of $28 \mathrm{~S}$ rDNA. 
However, Singh et al. (2006) showed that significant differences do exist between these two species in extended 28S rDNA, ITS2 as well as in cytochrome oxidase II, with a high degree of divergence. Surprisingly, this report was ignored by Kumar et al. creating confusion among the reader.

The across-the-board application of mere $\mathrm{COI}$ sequences for delimitation of closely related species or recently diverged species is a subject of controversy. The proponent of barcoding of life claims that interspecific variation in partial COI-mtDNA exceeds intraspecific variation by an arbitrary threshold called "barcoding gap". Although DNA barcode has successfully been used for delimitation of species where sufficient gap exists between intra- and interspecific $\mathrm{COl}$ sequence divergence, such gap often doesn't exist in closely related species or recently diverged species with incomplete lineage sorting. Considerable overlap in the range of intra- and interspecific $\mathrm{CO1}$ sequence divergence has been well documented (Meyer \& Paulay, 2005; Wiemers \& Fiedler, 2007). It was noted that a high proportion of well-differentiated species has similar or even identical CO1 sequences (Wiemers \& Fiedler, 2007; Conflitti et al., 2012). Among 449 dipteran species, Meier et al., (2006) find a low success rate $(<70 \%)$ based on tree-based and newly proposed species identification criteria of the barcode system. In the case of butterflies, Only $77 \%$ of species could be accurately identified using the barcode data (Eliass et al., 2007). In mosquitoes, Carter et al. (2019) noted that COl can not differentiate An. gambiae and sister species An. arabiensis. Even the whole mitochondrial genome of An. arabiensis, An. gambiae and An. coluzzii failed to show clear species division (Hanemaaijer et al., 2018). Several studies have reported discordant patterns between mtDNA and nuclear markers, commonly referred to as 'mito-nuclear discordant' (Toews \& Brelsford, 2012; Després, 2019). It has been proposed that this discordance may be due to incomplete lineage sorting or introgression (Toews \& Brelsford, 2012); however, some reports shows that the discordance cannot be explained by incomplete lineage sorting or introgression (Ivanov et al., 2018; Hinojosa et al., 2019). It has been proposed to use multiple nuclear and mitochondrial genes for delimitation of species (Vences et al., 2005; Beebe, 2018) and adopting integrative taxonomy approaching genetics, morphology, ecology, behaviour and geography (several references cited by Fis $\square$ er et al., 2018). Whatever method is used for species delimitation, one should consider important genetic principles lying with speciation, i.e., cessation of gene flow or genetic isolation which is a primary pointer of ongoing speciation (Bock, 2004). Additional data on molecular markers demonstrating gene flow restriction between $\mathrm{S}$ and $\mathrm{T}$ of the Fluviatilis Complex, crossing experiments, etc, is suggested in view of mito-nuclear discordance.

In conclusion, there is no plausible evidence so far indicating a breakthrough in reproductive isolation between An. fluviatilis species S and T so far in a sympatric population. The absence of a genetic barcode gap between species $\mathrm{S}$ and $\mathrm{T}$ may be due to retention of ancestral polymorphisms or possible introgression, which is not enough to prove synonymy in a condition when fixed differences in nuclear ITS2 do exist between these two species with no signature of hybridization. The inferred heterozygosity between species $\mathrm{S}$ and $\mathrm{T}$ through an ITS2 based species diagnostic assay by Kumar et al. is ruled out due to the high mispriming tendency of Tspecific primer. Contrast difference in host-selection attributes further supports their independent biological entity. Further study is required to confirm the genetic isolation among all members of the Fluviatilis Complex, preferably in a sympatric population.

\section{Authors' Contribution}

OPS designed and executed research, wrote the first draft of the manuscript, AS, GS and SM performed PCR, cloning and sequencing, SKS, PKS and MKD carried out fieldwork and sampling of mosquitoes. All authors have read and approved the final version of the manuscript.

\section{Acknowledgements}


The work was supported by the Indian Council of Medical Research (ICMR) project grant (6/9-7(17)/2013ECD-II). AS was supported by the Department of Science \& Technology fellowship, GS and SM were supported by the Indian Council of Medical Research Fellowship. Authors are grateful to Dr SK Subbarao for the critical review of the manuscript and constructive suggestions.

\section{References}

Beebe NW. DNA barcoding mosquitoes: advice for potential prospectors. Parasitology. 2018;145(5):622-633. doi: $10.1017 /$ S0031182018000343.

Beebe NW, Saul A. Discrimination of all members of the Anopheles punctulatus complex by polymerase chain reaction-restriction fragment length polymorphism analysis. Am J Trop Med Hyg. 1995;53(5):478-81. doi: 10.4269/ajtmh.1995.53.478. PMID: 7485705.

Bock WJ. Species: the concept, category and taxon. J Zool Syst Evol Res. 2004 42: 178-190.

Carter TE, Yared S, Hansel S, Lopez K, Janies D. Sequence-based identification of Anopheles species in eastern Ethiopia. Malar J. 2019;18(1):135. doi: 10.1186/s12936-019-2768-0. PMID: 30992003

Chen B, Butlin RK, Pedro PM, Wang XZ, Harbach RE. Molecular variation, systematics and distribution of the Anopheles fluviatilis complex in southern Asia. Med Vet Entomol. 2006; 20:33-43

Conflitti IM, Shields GF, Currie DC. A “complex" problem: delimiting sibling species boundaries in black flies (Diptera: Simuliidae). Can. Entomol. 2012;144: 323-336.

Després L. One, two or more species? Mitonuclear discordance and species delimitation. Mol Ecol. 2019;28:3845-3847. https ://doi.org/10.1111/mec.15211

Elias M, Hill RI, Willmott KR, Dasmahapatra KK, Brower AV, Mallet J, Jiggins CD. Limited performance of DNA barcoding in a diverse community of tropical butterflies. Proc Biol Sci. 2007;274(1627):2881-9.

Fišer C, Robinson CT, Malard F. Cryptic species as a window into the paradigm shift of the species concept. Mol Ecol. 2018;27(3):613-635. doi: 10.1111/mec.14486.

Garros C, Harbach RE, Manguin S. Morphological assessment and molecular phylogenetics of the Funestus and Minimus groups of Anopheles (Cellia). J Med Entomol. 2005;42(4):522-36.

Hanemaaijer MJ, Houston PD, Collier TC, Norris LC, Fofana A, Lanzaro GC, Cornel AJ, Lee Y. Mitochondrial genomes of Anopheles arabiensis, An. gambiae and An. coluzzii show no clear species division. F1000Res. 2018; 7:347. doi: 10.12688/f1000research.13807.2.

Hinojosa JC, Koubínová D, Szenteczki MA, Pitteloud C, Dincă V, Alvarez N, Vila R. A mirage of cryptic species: Genomics uncover striking mitonuclear discordance in the butterfly Thymelicus sylvestris. Mol Ecol. 2019;28(17):3857-3868. doi: 10.1111/mec.15153.

Ivanov V, Lee KM, Mutanen M. Mitonuclear discordance in wolf spiders: Genomic evidence for species integrity and introgression. Mol Ecol. 2018;27(7):1681-1695. doi: 10.1111/mec.14564.

Kumar NP, Krishnamoorthy N, Sahu SS, Rajavel AR, Sabesan S, Jambulingam P. DNA barcodes indicate members of the Anopheles fluviatilis (Diptera: Culicidae) species complex to be conspecific in India. Mol Ecol Resour. 2013;13(3):354-61. doi: 10.1111/1755-0998.12076.

Manonmani A, Townson H, Adeniran T, Jambulingam P, Sahu S, Vijayakumar T. rDNA-ITS2 polymerase chain reaction assay for the sibling species of Anopheles fluviatilis. Acta Trop. 2001;78(1):3-9.

Meier R, Shiyang K, Vaidya G, Ng PK. DNA barcoding and taxonomy in Diptera: a tale of high intraspecific variability and low identification success. Syst Biol. 2006;55(5):715-28. doi: 10.1080/10635150600969864.

Meyer CP, Paulay G. DNA barcoding: error rates based on comprehensive sampling. PLoS Biol. 2005; 3(12): 422

Mishra S, Sharma G, Das MK, Pande V, Singh OP. Intragenomic sequence variations in the second internal transcribed spacer (ITS2) ribosomal DNA of the malaria vector Anopheles stephensi. PloS one, 2021; 16(6), e0253173. https://doi.org/10.1371/journal.pone.0253173 
Nanda N, Bhatt RM, Sharma SN, Rana PK, Kar NP, Sharma A, Adak T. Prevalence and incrimination of Anopheles fluviatilis species S (Diptera: Culicidae) in a malaria endemic forest area of Chhattisgarh state, central India. Parasit Vectors. 2012 5:215

Nanda N, Joshi H, Subbarao SK, Yadav RS, Shukla RP, Dua VK, Sharma VP. Anopheles fluviatilis complex: host feeding patterns of species S, T, and U. J Am Mosq Control Assoc. 1996;12(1):147-9.

Nanda N, Singh OP, Dua VK, Pandey AC, Nagpal BN, Adak T, Dash AP, Subbarao SK. Population cytogenetic and molecular evidence for existence of a new species in Anopheles fluviatilis complex (Diptera: Culicidae). Infect Genet Evol. 2013;13:218-23. doi: 10.1016/j.meegid.2012.09.018.

Nanda N, Yadav RS, Subbarao SK, Joshi H, Sharma VP. Studies on Anopheles fluviatilis and Anopheles culicifacies sibling species in relation to malaria in forested hilly and deforested riverine ecosystems in northern Orissa, India. J Am Mosq Control Assoc. 2000;16(3):199-205.

Sahu SS, Gunasekaran K, Jambulingam P. Bionomics of Anopheles minimus and An. fluviatilis (Diptera: Culicidae) in east-central India, endemic for falciparum malaria: human landing rates, host feeding, and parity. J Med Entomol. 2009;46(5):1045-51. doi: 10.1603/033.046.0511. PMID: 19769035.

Sahu SS, Gunasekaran K, Vanamail P, Jambulingam P. Seasonal prevalence and resting behaviour of Anopheles minimus Theobald \& An. fluviatilis James (Diptera: Culicidae) in east-central India. Indian J Med Res. 2011;133:655-61.

Sharma D, Lather M, Dykes CL, Dang AS, Adak T, Singh OP. Disagreement in genotyping results of drug resistance alleles of the Plasmodium falciparum dihydrofolate reductase (Pfdhfr) gene by allele-specific PCR (ASPCR) assays and Sanger sequencing. Parasitol Res. 2016;115:323-8. doi: 10.1007/s00436-0154750-2.

Sharma G, Lather M, Singh OP. Variations in palpal ornamentation of Anopheles fluviatilis species T and U (Diptera: Culicidae) and their taxonomic consequence. Indian J Exp Biol. 2020; 58: 64-68

Sharma SK, Tyagi PK, Padhan K, Upadhyay AK, Haque MA, Nanda N, Joshi H, Biswas S, Adak T, Das BS, Chauhan VS, Chitnis CE, Subbarao SK. Epidemiology of malaria transmission in forest and plain ecotype villages in Sundargarh District, Orissa, India. Trans R Soc Trop Med Hyg. 2006 Oct;100(10):917-25.

Sharma SK, Nanda N, Dua VK, Joshi H, Subbarao SK, Sharma VP. Studies on the bionomics of Anopheles fluviatilis sensu lato and the sibling species composition in the foothills of Shiwalik range (Uttar Pradesh), India. SE Asian J Trop Med Parasitol, 1995; 26:566-572.

Shukla RP, Nanda N, Pandey AC, Kohli VK, Joshi H, Subbarao SK. Studies on bionomics of Anopheles fluviatilis and its sibling species in Nainital district, UP. Indian J Malariol. 1998;35:41-47.

Singh N, Mishra AK, Chand SK, Bharti PK, Singh MP, Nanda N, Singh OP, Sodagiri K, Udhyakumar V. Relative abundance and Plasmodium infection rates of malaria vectors in and around Jabalpur, a malaria endemic region in Madhya Pradesh state, Central India. PLoS One. 2015;10(5):e0126932. doi: 10.1371/journal.pone.0126932.

Singh OP, Chandra D, Nanda N, Raghavendra K, Sunil S, Sharma SK, Dua VK, Subbarao SK. Differentiation of members of the Anopheles fluviatilis species complex by an allele-specific polymerase chain reaction based on 28S ribosomal DNA sequences. Am J Trop Med Hyg. 2004;70(1):27-32.

Singh OP, Chandra D, Nanda N, Sharma SK, Htun PT, Adak T, Subbarao SK, Dash AP. On the conspecificity of Anopheles fluviatilis species S with Anopheles minimus species C. J Biosci. 2006; 31:671-7

Singh OP, Nanda N, Chandra D, Jha D, Adak T, Dua VK, Subbarao SK. Modified PCR-based assay for the differentiation of members of Anopheles fluviatilis complex in consequence of the discovery of a new cryptic species (species V). Malar J. 2020 Feb 27;19(1):96. doi: 10.1186/s12936-020-03172-1.

Singh OP, Nanda N, Dev V, Bali P, Sohail M, Mehrunnisa A, Adak T, Dash AP. Molecular evidence of misidentification of Anopheles minimus as Anopheles fluviatilis in Assam (India). Acta Trop. 2010;113:241-4.

Subbarao SK, Nanda N, Vasantha K, Dua VK, Malhotra M S, Yadav RS, Sharma VP. Cytogenetic evidence for three sibling species in Anopheles fluviatilis (Diptera: Culicidae). Ann Entomol Soc Am. 1994; $87: 116-121$ 
Toews DP, Brelsford A. The biogeography of mitochondrial and nuclear discordance in animals. Mol Ecol. 2012;21(16):3907-30. doi: 10.1111/j.1365-294X.2012.05664.x.

Tripathy A, Samanta L, Das S, Parida SK, Marai N, Hazra RK, Kar SK, Mahapatra N. Distribution of sibling species of Anopheles culicifacies s.l. and Anopheles fluviatilis s.l. and their vectorial capacity in eight different malaria endemic districts of Orissa, India. Mem Inst Oswaldo Cruz. 2010;105:981-7

Vences M, Thomas M, Bonett RM, Vieites DR. Deciphering amphibian diversity through DNA barcoding: chances and challenges. Philos Trans R Soc Lond B Biol Sci. 2005;360(1462):1859-68.

Wiemers M, Fiedler K. Does the DNA barcoding gap exist? - a case study in blue butterflies (Lepidoptera: Lycaenidae) Frontiers in Zoology 2007, 4:8 


\begin{tabular}{|c|c|c|c|}
\hline An. fluviatilis $\mathrm{T}$ & 1 & АCCAATTCCTTGTTACACACTATTCTAACTACATGGCGCCCGTGTACGGA & 50 \\
\hline & & 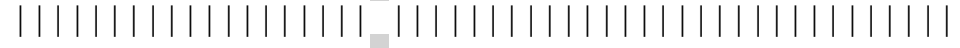 & \\
\hline An. fluviatilis $\mathrm{S}$ & 1 & ACCAATTCCTTGTTACACAATATTCTAACTACATGGCGCCCGTGTACGGA & 50 \\
\hline An. fluviatilis $\mathrm{T}$ & 51 & CGGCATCATGGCGAGCAGCCCGCCTTCTGATGTTGCTGAAWGAACACGTG & 100 \\
\hline An. fluviatilis $\mathrm{S}$ & 51 & CGGCATCATGGCGAGCAGCCCGCCTTCTGATGTTGCTGAATGAACACGTG & \\
\hline An. fluviatilis $\mathrm{T}$ & 101 & AGCGCACTGTGCATCATTGCGTGCAGGGCCCGTCTCCTACCGGGAACCTT & 150 \\
\hline An. fluviatilis $\mathrm{S}$ & 101 & AGCGCACTGTGCATCATTGCGTGCAGGGCCCGTCTCCTACCGGGAACCTT & 150 \\
\hline An. fluviatilis $\mathrm{T}$ & 151 & GGGCGCTGAAACAGGTAAGGCAGTGCAGTGTTACTGTACAATTTGGGKGG & 200 \\
\hline & & |||||||||||||||||||||||||||||||||||||| $\mid$ & \\
\hline An. fluviatilis $\mathrm{S}$ & 151 & GGGCGCTGAAA AGGTAAGGCAGTACAGTTCCACTGTACAATTTGGG GG & 198 \\
\hline An. fluviatilis $\mathrm{T}$ & 201 & TGCAGCGTCAAGTCGCACGGGTCGAACTTCGGCTATGGACGACCTGAGAT & 250 \\
\hline & & & \\
\hline An. fluviatilis $\mathrm{S}$ & 199 & TGCAGCGTCAAGTCGCACGGGTCGAACTTCGGCTATGGACGACCTGAGAT & 248 \\
\hline An. fluviatilis $\mathrm{T}$ & 251 & ACCCGGCAGCCTACTAACACCAGGCTTGTCGATAAGGTTCCAGGGGTTAC & 300 \\
\hline & & |||||||||||||||||||||||||||||||||||||||||||||||||||||| & \\
\hline An. fluviatılis $\mathrm{S}$ & 249 & ACCCGGCAGCCTACTAACACCAGGCTTGTCGACCAGGTTCCAGGGGTTAC & 29 \\
\hline An. fluviatilis $\mathrm{T}$ & 301 & GAATCATCCGGCCGAGTCGTGTAACGCGTGCGACCCATACGGTGCACCCA & 350 \\
\hline & & \|\|\|\|\|\|\|\|\|\|\|\|\|\|\|\|\|\|\|\|\|\|\|\|$\|$ & \\
\hline An. fluviatılls $\mathrm{S}$ & 299 & GAATCATCCGGCCGAGTCGTGTAACGCGTGCGACCCATACGGTGCACCCA & \\
\hline An. fluviatilis $\mathrm{T}$ & 351 & TGTTTAATTGGCAACCTACCTTTACAAGT & \\
\hline & & $\|||||||||||||||||||||||||$ & \\
\hline An. fluviatilis $\mathrm{S}$ & 349 & TGTTTAGATGGCAACCTACCTTCATAAGT & \\
\hline
\end{tabular}

Figure 1 Sequence alignment of species ITS2-rDNA of species $S$ and T. The differences in nucleotide sequences are highlighted. 


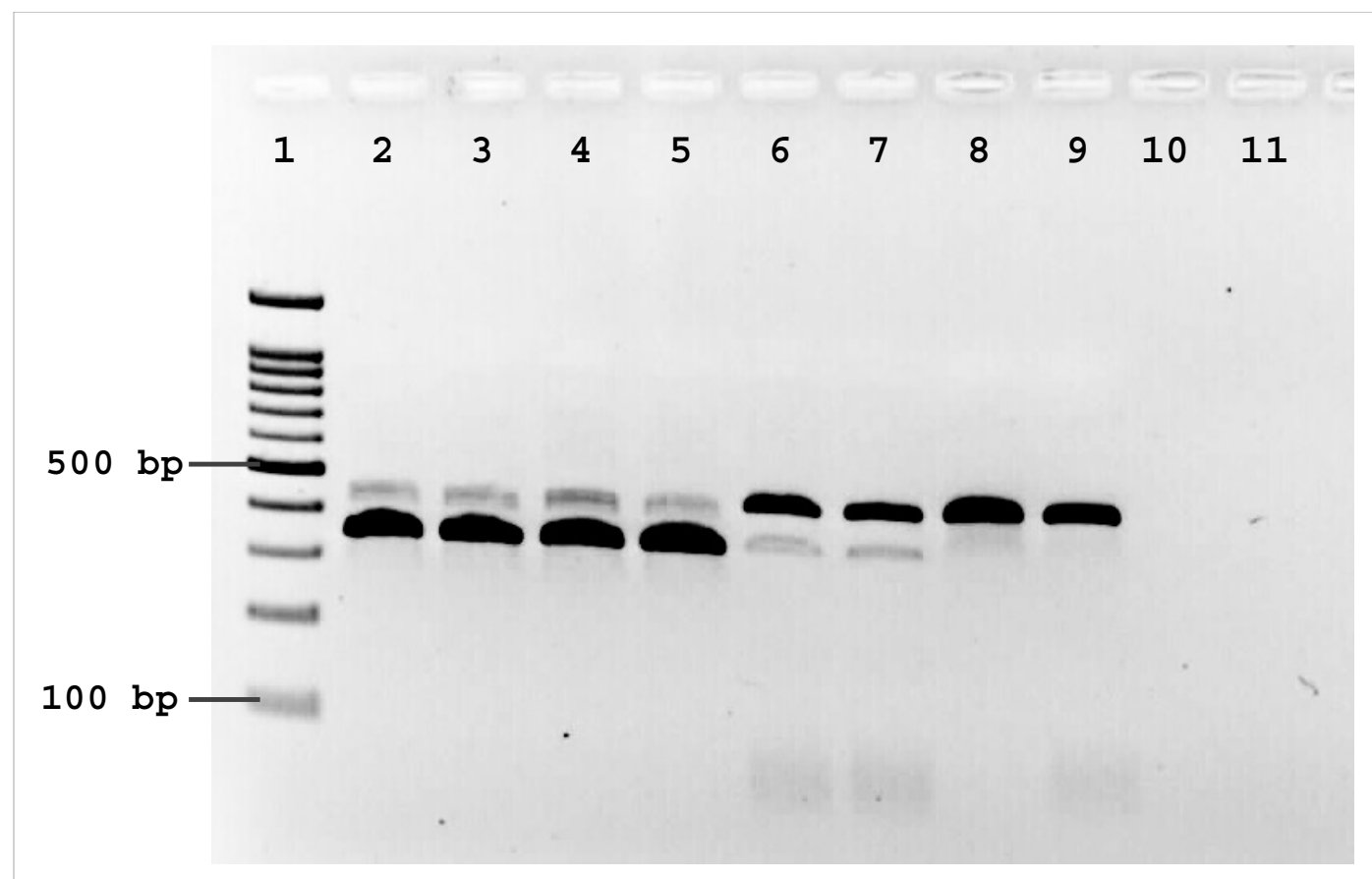

Figure 2 Species-diagnostic PCR (Manonmani et al., 2001) showing cross-reactivity of T-R. with species $S$ and An. minimus s.s. The size of species T- and S-specific amplicons are 345 and 450 bp, respectively. Lanes 2 \& 3: species $S$, lanes 4 \& 5: clonal $S$ samples; lanes 6 \& 7: An. minimus, lanes 8 \& 9: species T; lane 1: 100 bp DNA ladder, lane 10: negative control without DNA, lane 11: negative control with pGemT easy vector.

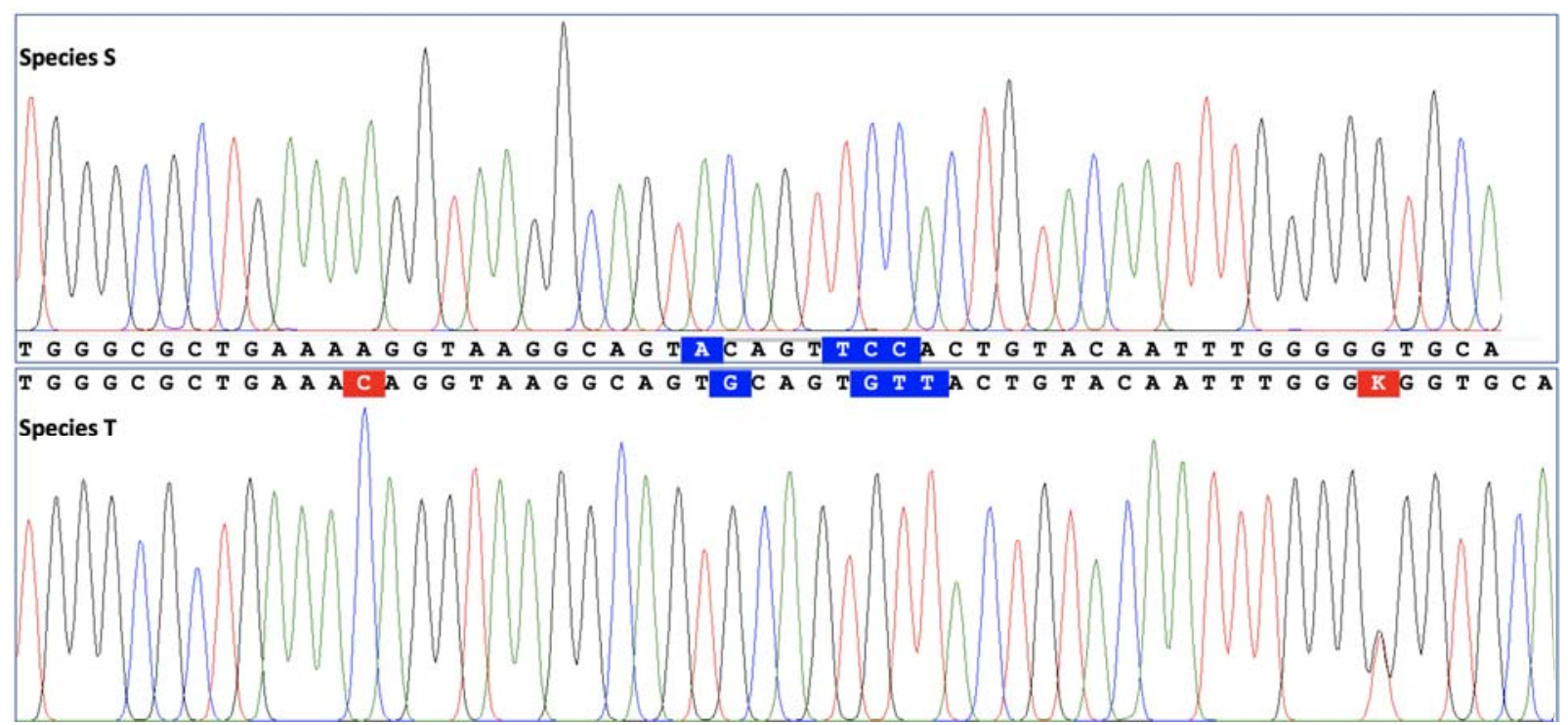

Figure 3 DNA sequence chromatograms of a portion of ITS2-rDNA of species $S$ and $T$ showing nucleotide sequence and length polymorphism. The species $S$ sequence shown here belongs to a sample that showed the presence of both species $S$ and $T$ diagnostic amplicon in ITS2-based species diagnostic assay. It may be noted that there is no signature of heterozygote in the DNA sequence. The nucleotide differences in sequences are highlighted (indels with red colour and substitutions with blue colour). 


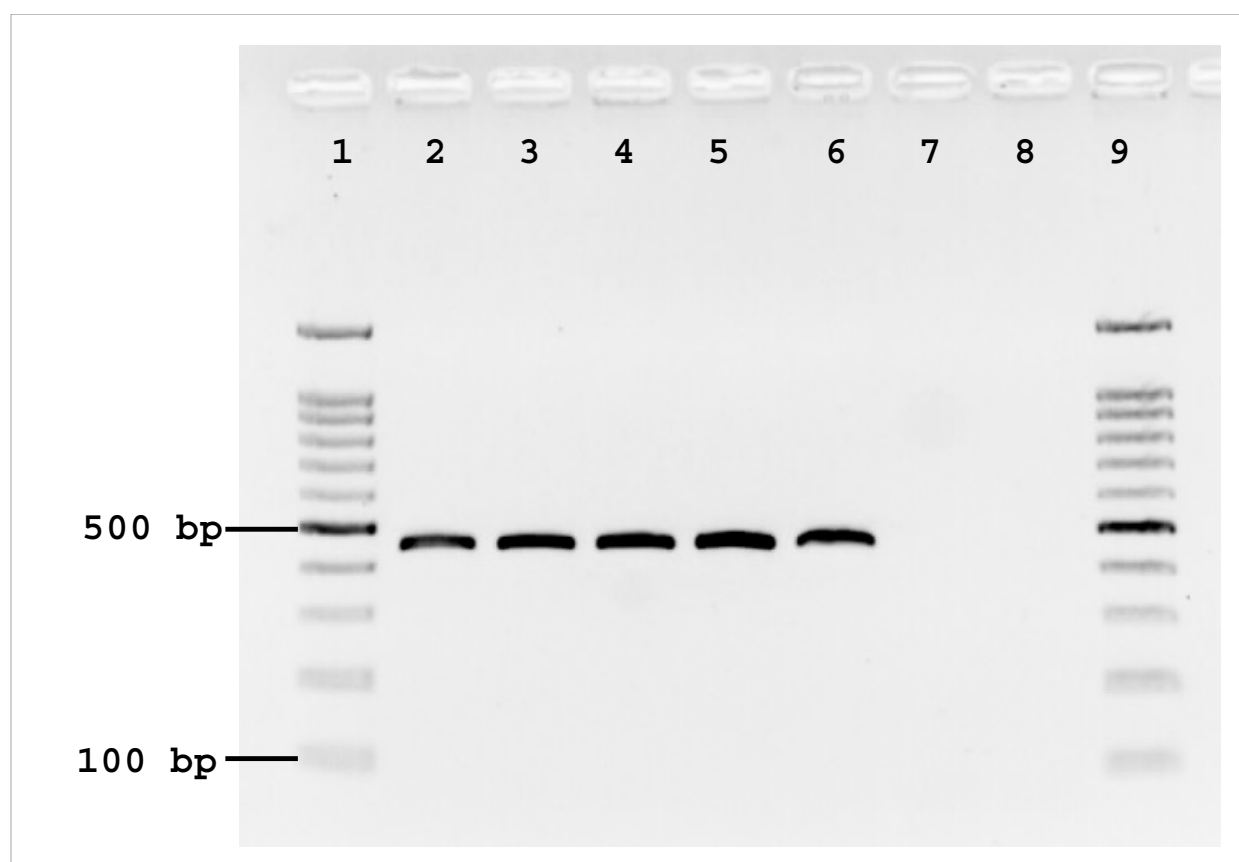

Figure 4 PCR products (450 bp) amplified with primers 5.8S-F and T-R (T-specific) on clonal samples of species $S$ (ITS2) showing mispriming of T-R with species $S$ template. Lanes $1 \&$ 9: 100 bp DNA ladder; lanes 2-6: clonal sample of species S; lane 7: negative control with DNA, lane 8: negative control with pGemT easy vector 


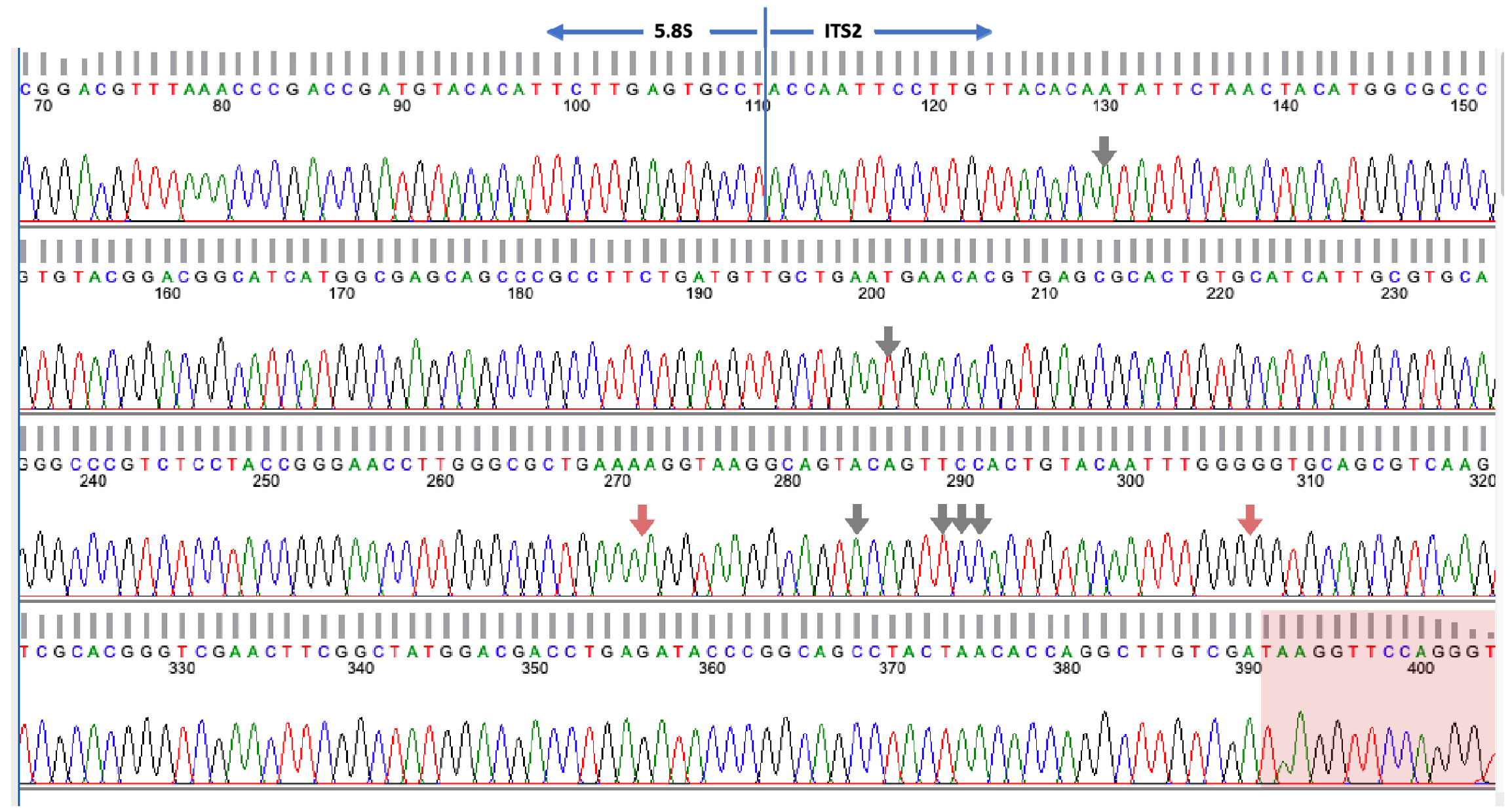

Figure 5 DNA sequence chromatogram of non-specific primer extension product amplified with universal primer 5.8SF and T-specific primer (T-R) on species $S$ clonal template. The amplified product is identical to species $S$ sequence except in primer region (highlighted with pink colour) which is derived from T-R primer. Vertical arrows indicate base positions where species $S$ and differs from species $T$ (grey arrow=substitution; orange arrow=indel) 


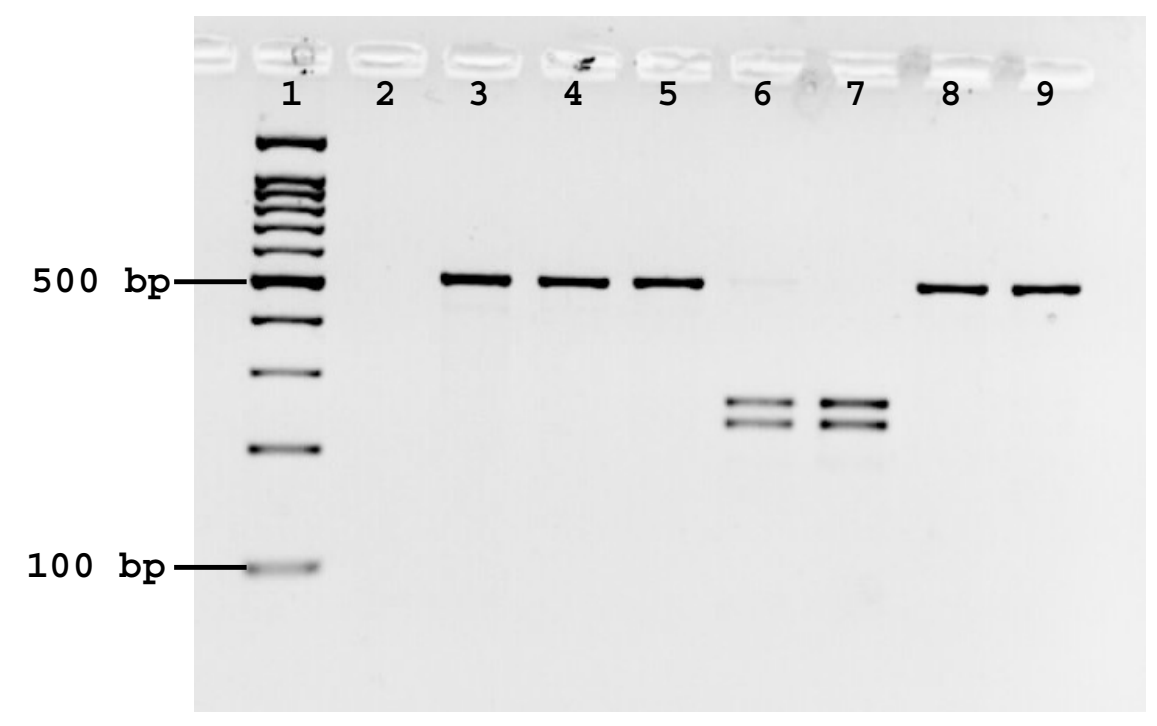

Figure 6 Results of PCR-RFLP (BtsI-v2) on species S and T samples. The PCR products amplified with ITS2A and ITS2C were subjected to restriction digestion. Lane 1: 100 bp ladder; lane 2: negative control, without DNA; lanes 3-5: species S; lanes 6 \& 7: species T; lanes 8 \& 9: species $S$ and T, respectively. without enzyme treatment. 